\title{
Gold Brazing in Antiquity
}

\section{TECHNICAL ACHIEVEMENTS IN THE EARLIEST CIVILISATIONS}

\section{P. M. Roberts}

Johnson Matthey \& Co Limited, London

Gold brazing alloys are employed today in a variety of specialised applications requiring high joint strength combined with resistance to oxidation or corrosion. While sophisticated brazing methods are now used, a study of the technique of gold brazing in the first civilisations shows a remarkable degree of metallurgical skill and craftsmanship.

Recent advances in aero-space, nuclear and electronic engineering have demanded the development of brazing alloys capable of producing joints of high strength at elevated temperatures and that are able to withstand a wide range of oxidising and corrosive environments. It is frequently the case that these requirements can be satisfied only when gold forms the major constituent of the brazing alloy.

An earlier article by $M$. H. Sloboda in this journal reviewed the properties and advantages of goldbased brazing alloys and described typical examples of their use in modern industry. Similar alloys have, of course, been used for many hundreds of years in the fabrication of gold jewellery, but the present article is concerned with the techniques of brazing with gold alloys developed during the second and third millenia B.C.

Obviously, brazing technology could not have been developed until the introduction of the use of metals. While some evidence exists that native copper was cold-worked at even earlier times, by about 4400 B.C. axe heads were being cast in copper, silver
Gold brazing was known and skilfully practised by the Sumerians-the first civilisation in the history of man-in the third millenium B.C. This gold goblet, now in the British Museum, was excavated by Sir Leonard Woolley in the Royal Cemetery at Ur. It was found, still filled with green eye paint, in the tomb of Queen Pu-abi and is dated approximately 2500 B.C. It is made in a 25 per cent silver-gold alloy, generally referred to as electrum, and its construc. tion is quite remarkable; the upper portion is double walled, and a brazed joint was made round the periphery as shown in the sketch below
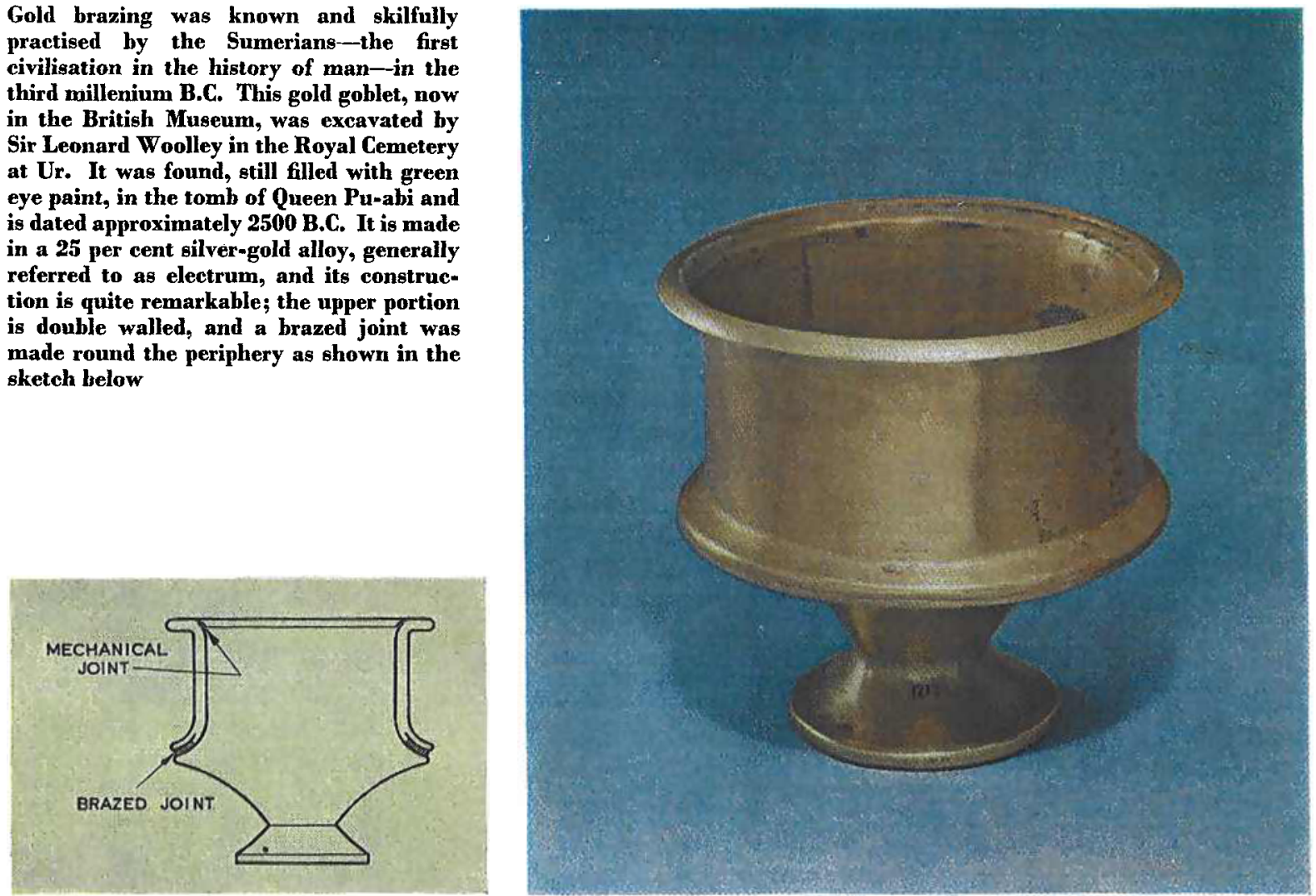
A gold bowl, also from the tomb of Queen Pu-abi and dated to 2500 B.C. The body is beaten from one sheet of silver-gold alloy, the twisted wire handle being attached by tubular lugs brazed to the bowl. The fillet of the brazed joint can be clearly seen in the close-up view below
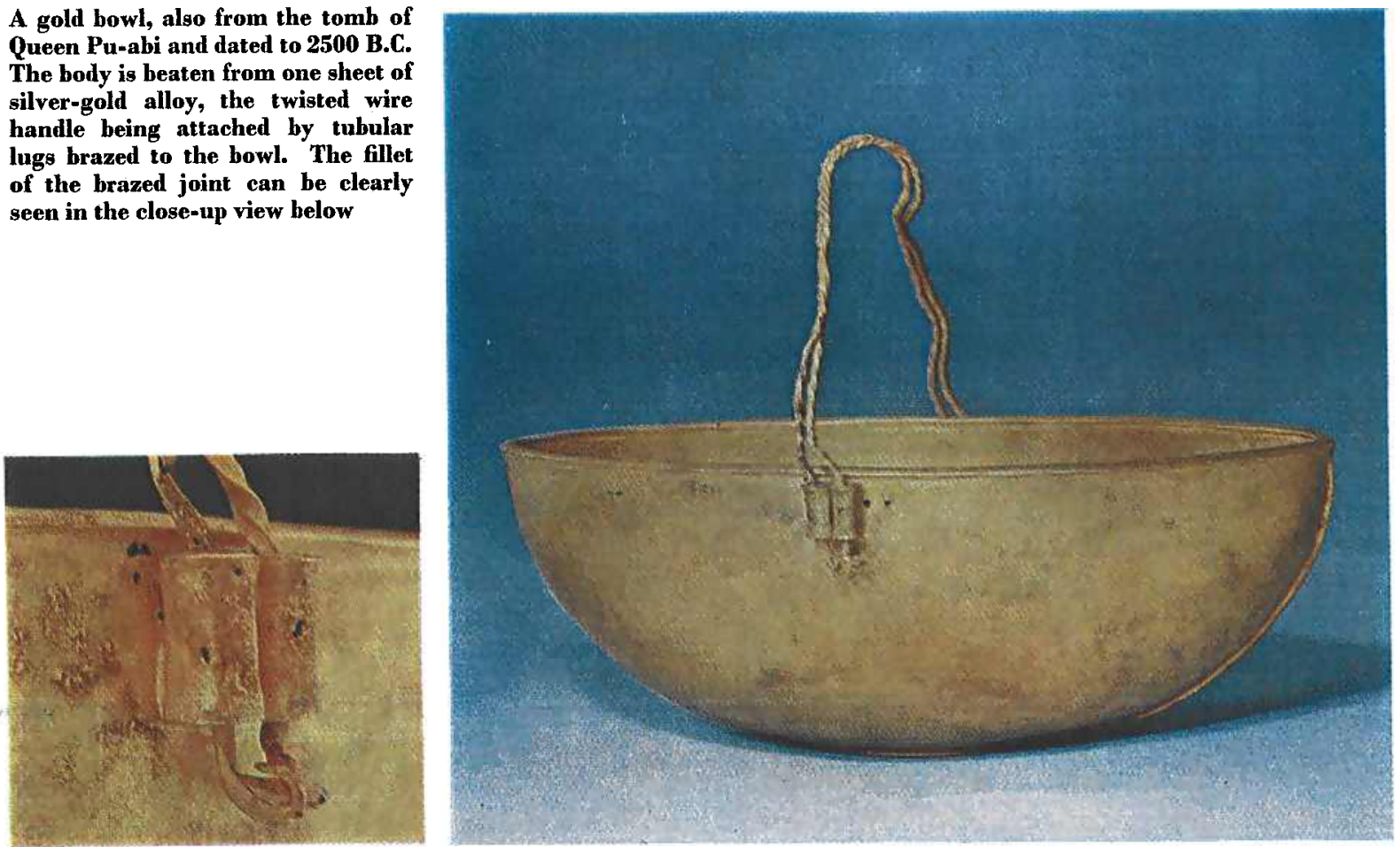

and lead were being used, and objects of gold had made their first appearance in the land of Sumer, the area lying between the rivers Tigris and Euphrates in what is now Iraq. It was in this area, later to be known as Babylonia, and then as Mesopotamia, that our first civilisation was born and the practice of metallurgy began.

The craft of the metal-worker doubtless developed very slowly in these early times, but before very long the idea would have occurred that by joining together two or more pieces of metal a great advance could be made in the fabrication of vessels, implements and jewellery. Riveting was undoubtedly in use in the third millenium B.C., but by this time brazing had also made its appearance.

Some confusion has arisen in the archaeological literature over the terms soldering, brazing and welding, while the use of other loose phrases such as "sweating" or "autogenous soldering" has further obscured the facts. The term brazing (hard soldering)

A charcoal fire in a clay bowl, a reed tipped with clay for a blowpipe, and tongs to hold the parts to be brazed. These were the primitive equipment of the goldsmith in antiquity, and yet he was able to produce vessels and jewellery displaying the highest standards of craftsmanship. This drawing, from a wall painting in the tomb of the Vizier Rekh-mi-re at Thebes, dating from about 1475 B.C., shows a metal worker engaged in brazing in the workshop attached to the temple of Amun at Karnak is now established as meaning the production of a joint by means of an alloy of reasonably high strength having a melting point somewhat lower than that of the metals or alloys to be joined, while soldering (soft soldering) refers to the use of alloys of low melting point such as the well known tin-lead solders.

Now the essential requirements for successful brazing are, of course, a means of achieving a high temperature - in excess of the melting point of the brazing alloy-and a method of ensuring that the surfaces of both the parent metals to be joined and

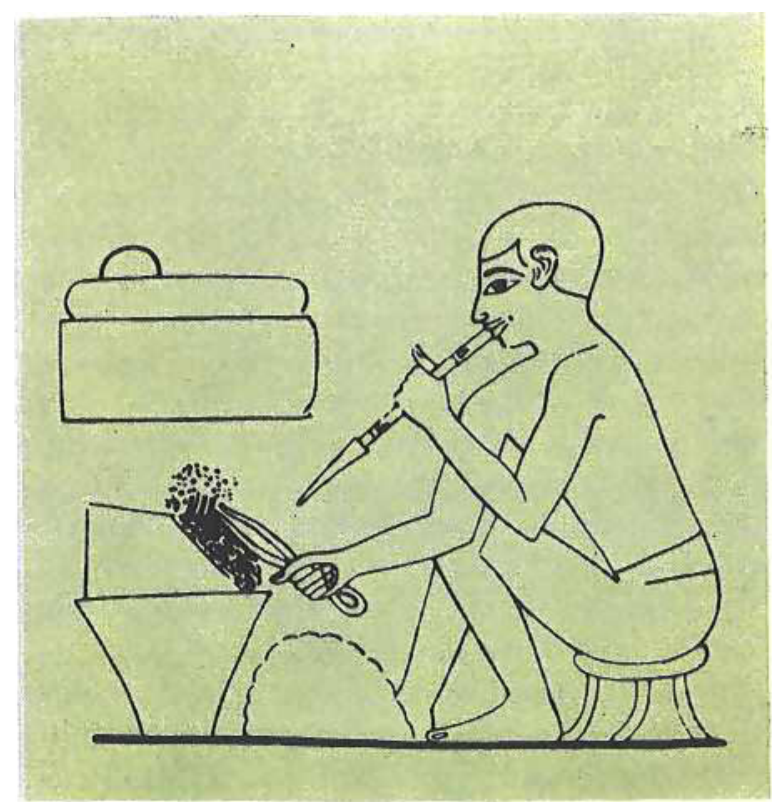


of the brazing alloy itself are free from oxide films at the brazing temperature. While early metallurgy probably began in the domestic fire or even in the paths of forest fires, the first extraction processes for metals such as copper, lead and silver were carried out in charcoal fires with forced draught provided by men with blowpipes. It is possible that the phenomenon of brazing was discovered accidentally in the fourth millennium B.C. in one of these primitive furnaces.

In modern brazing practice the removal of oxide films is usually accomplished by the use of a fusible flux that will dissolve the oxides on both surfaces, by the use of an inert atmosphere such as nitrogen or argon, by heating the assembly in a vacuum, or by the use of a protective atmosphere containing a reducing gas, such as carbon monoxide or hydrogen, that will react with the oxides present, reducing them to metal.

Obviously neither inert gases nor vacuum furnaces were available at the times in question, and the early brazing processes must have been based either on the use of chemical fluxes or on the reducing atmosphere of carbon monoxide generated in a charcoal fire or on a combination of both.

\section{The Choice of Brazing Alloy}

Pure gold, as is well known, is entirely free from oxide films, but when alloyed with silver or copper this is no longer the case, and practically all the gold objects associated with the early civilisations were very far from pure, usually containing between about 60 to 75 or 80 per cent of gold, the balance consisting of silver or copper or, more commonly, both. The selection of a brazing alloy for use in the fabrication of gold articles was thus a matter of some considerable difficulty. It is likely that the early metal workers observed that gold obtained from certain areas, or differing in colour, tended to melt more readily than others, although it is also possible that intentional alloying - an idea derived from the alloying of tin with copper to produce bronze-was practised to some extent.

To consider this problem in more detail we need to look at the melting ranges of the alloys of gold with copper, with silver, and with both these metals. The diagrams show that alloys of gold and copper form a continuous series of solid solutions, with a minimum in the melting range at $910^{\circ} \mathrm{C}$ with 20 per cent of copper. In the gold-silver system a continuous series of solid solutions is again in evidence, but with no minimum in the melting range. The alloy of some 25 per cent silver, generally referred to as electrum, is seen to have a melting range of about $1030^{\circ}$ to $1040^{\circ} \mathrm{C}$. To represent the melting range of the ternary gold-copper-silver alloys is a little more

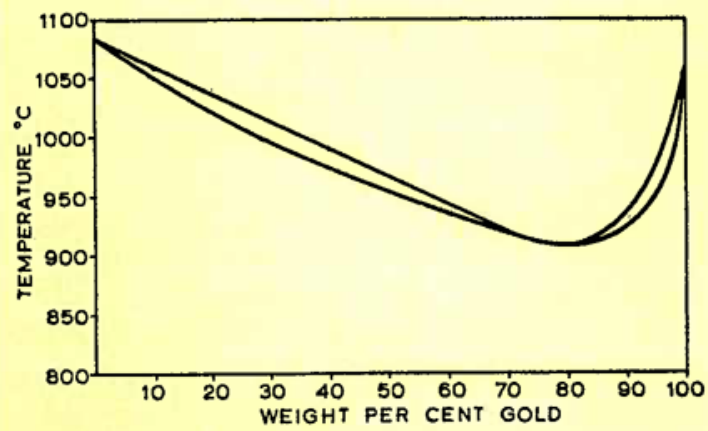

Gold and copper form a continuous series of solid solutions with a very narrow melting range which makes them very suitable as brazing alloys. At 20 per cent of copper the liquidus and solidus curves converge at a single melting point of $910^{\circ} \mathrm{C}$

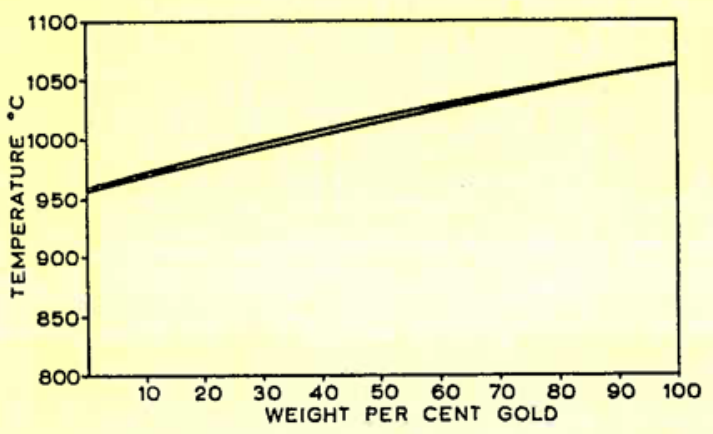

Alloys of gold and silver also form a continuous series of solid solutions but with no minimum in the melting range, which descends smoothly from the gold point at $1063^{\circ} \mathrm{C}$ to the silver melting point at $961^{\circ} \mathrm{C}$. Again the liquidus and solidus curves are very close together, giving good brazing properties

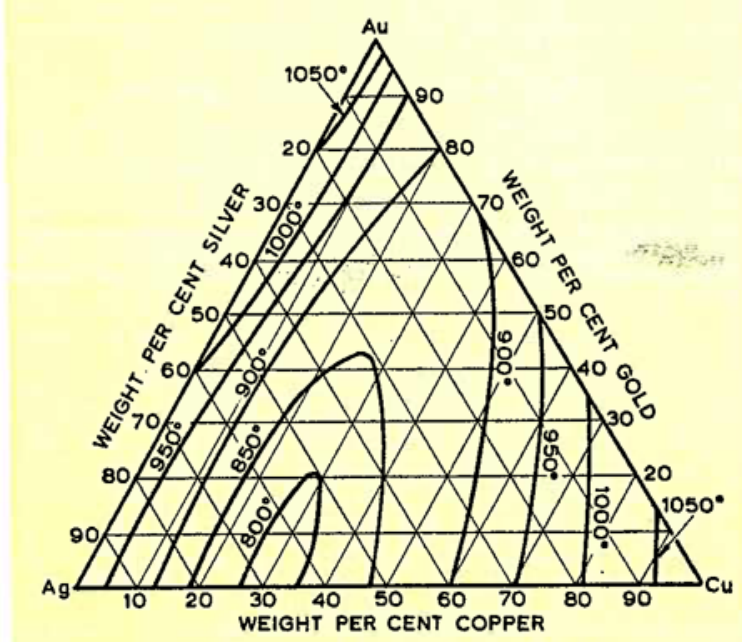

The liquidus curves of the ternary gold-silver-copper alloys extensively used as brazing media from the very beginnings of metal working techniques. It will be seen that a trough in the liquidus values extends across the diagram from the eutectic silver-copper alloy melting at $778^{\circ} \mathrm{C}$ to the minimum in the goldcopper liquidus curve at $910^{\circ} \mathrm{C}$ 
One of many objects found by Heinrich Sehliemann during his excavation of Troy, this double-spouted drinking vessel is dated approximately 2200 B.C. The body was beaten from one sheet of nearly pure gold, the handles were made separately by brazing from sheet metal, and were then attached to the body by brazing

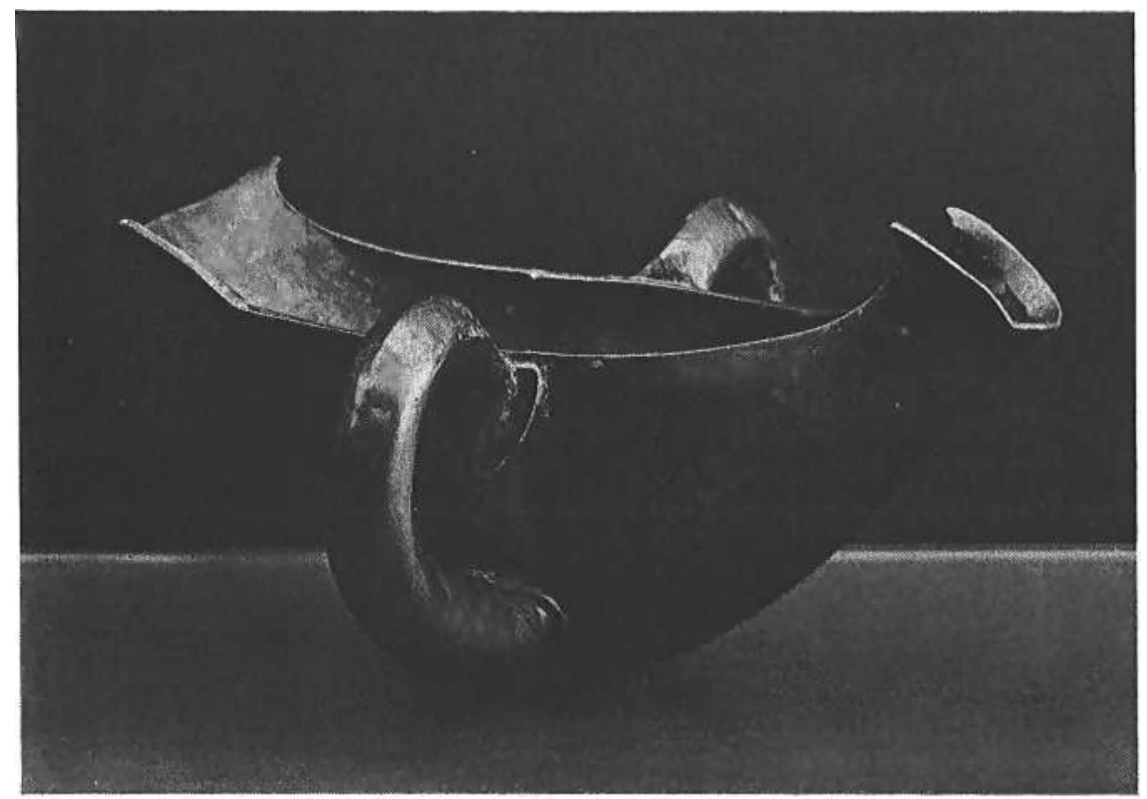

complicated, but the diagram shows the range of liquidus temperatures-at which they are completely liquid-for these alloys. From modern metallurgical knowledge it is clearly possible to select for use as a brazing material alloys having melting ranges anywhere between, say, $850^{\circ}$ and $1020^{\circ} \mathrm{C}$, but of course the Sumerian or Egyptian metal worker had to rely either upon the colour of his alloys or upon tedious trial and error methods.

\section{Early Brazing Technique}

Small pieces or chips of the chosen brazing alloy would then have been laid in position, or held in position by small pieces of wire, around the joint to be made, a flux of some kind would have been applied to the surfaces to be joined, and the work put into a charcoal fire-or held by tongs in the fireuntil the brazing alloy became molten. The flame was then concentrated on the joint, with the reed blowpipe, and the brazing alloy would flow by capillary attraction into the space between the surfaces to be joined. Later, the metal worker would clean off residual traces of flux from the work, probably by scraping.

We have, unfortunately, no means of knowing the nature of the flux used for brazing in the earliest civilisations; it is doubtful if borax was known at this period, it is possible that the burnt lees of wine -referred to many centuries later by Theophilus-or that natron (sodium carbonate) were used, but there can be no certainty in the matter.

One of the characteristics of a brazed joint is the fillet of excess brazing alloy remaining just around the joint area, and it is relatively simple to identify such joints by inspection, although the degree of craftsmanship naturally varied in the extent to which

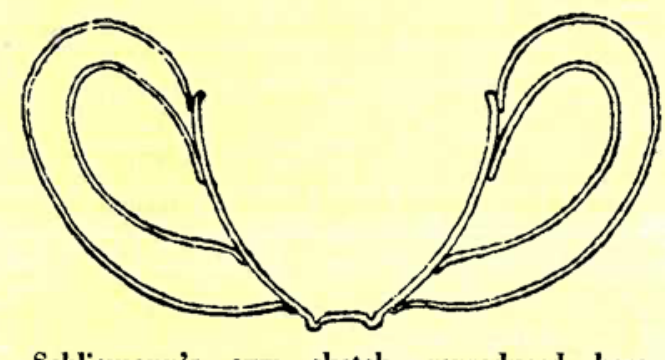

Schliemann's own sketch, reproduced here, shows the brazed construction of the vessel, which was probably used for ritual purposes. It was formerly in the Berlin Museum but unfortunately disappeared in 1945

a fillet was formed or was subsequently cleaned up or reduced by scraping. Such fillets are clearly visible in the joints illustrated on pages 112 and 113 in the objects from the royal graves at Ur, dated from about 2500 B.C., and from the double spouted drinking vessel from Troy, dating from around 2200 B.C., and shown above. The technique spread, probably in the hands of itinerant goldsmiths, along the trade routes linking Mesopotamia with Anatolia and other parts of Asia Minor, and similarly to Egypt and later on to Greece and even to Ireland.

Many hundreds of pieces of gold jewellery and vessels of various kinds can be seen in the leading museums of the world showing a fillet, or a streak of gold alloy of slightly different colour, along the joints in the work, and almost invariably the craftsmanship and technical skill displayed are of the very highest. In fact many of the joints made in these early civilisations, and the excellence of the workmanship that was achieved, would be difficult to 


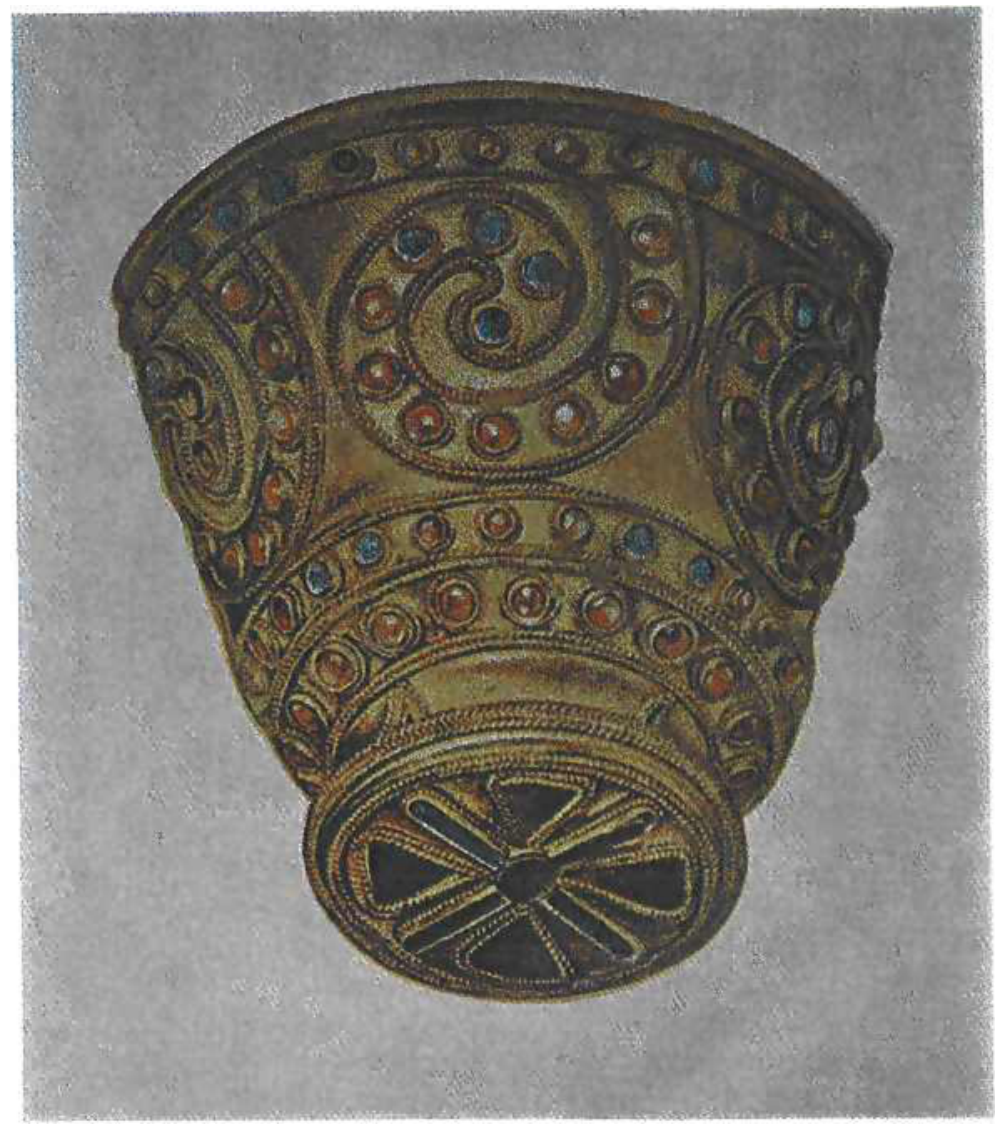

The intricate soldering techniques of granulation and filigree were also first practised by the Sumerians, but again the technique spread by the early trade routes to Phoenicia on the Mediterranean coast and, probably via Persia, to Transcaucasia. This remarkable gold cup, with filigree work inlaid with semi-precious stones, all surrounded by granulation, comes from a barrow grave at Trialeti, west of Tiflis in Georgia, and is now in the Hermitage in Leningrad. The date assigned to it by archaeologists is a little after 2000 B.C.

Photograph by Peter Clayton

emulate today despite the high degree of sophistication available both in technique and in brazing materials.

This was the method undoubtedly used for making major joints in vessels and similar objects, where the article would have to withstand a certain amount of stress in handling or in use. There was, however, an entirely different process, also first developed in the hands of Sumerian craftsmen around 2000 B.C., used mainly for decorative purposes.

\section{Diffusion Bonding}

This was the technique of applying either very fine wires or very small granules of gold-or both-

Both types of braxing technique are in evidence in the fabrication of these small sphinxes from Egypt. They were used as necklace clasps and date from about 1800 B.C. The uraeus or sacred snake on the head has been brazed into position by the diffusion method, while a smooth fillet between the tail and the haunch of each sphinx shows that these joints were made with another gold alloy as the brazing medium. These objects are in the Department of Egyptian Antiquities in the British Museum

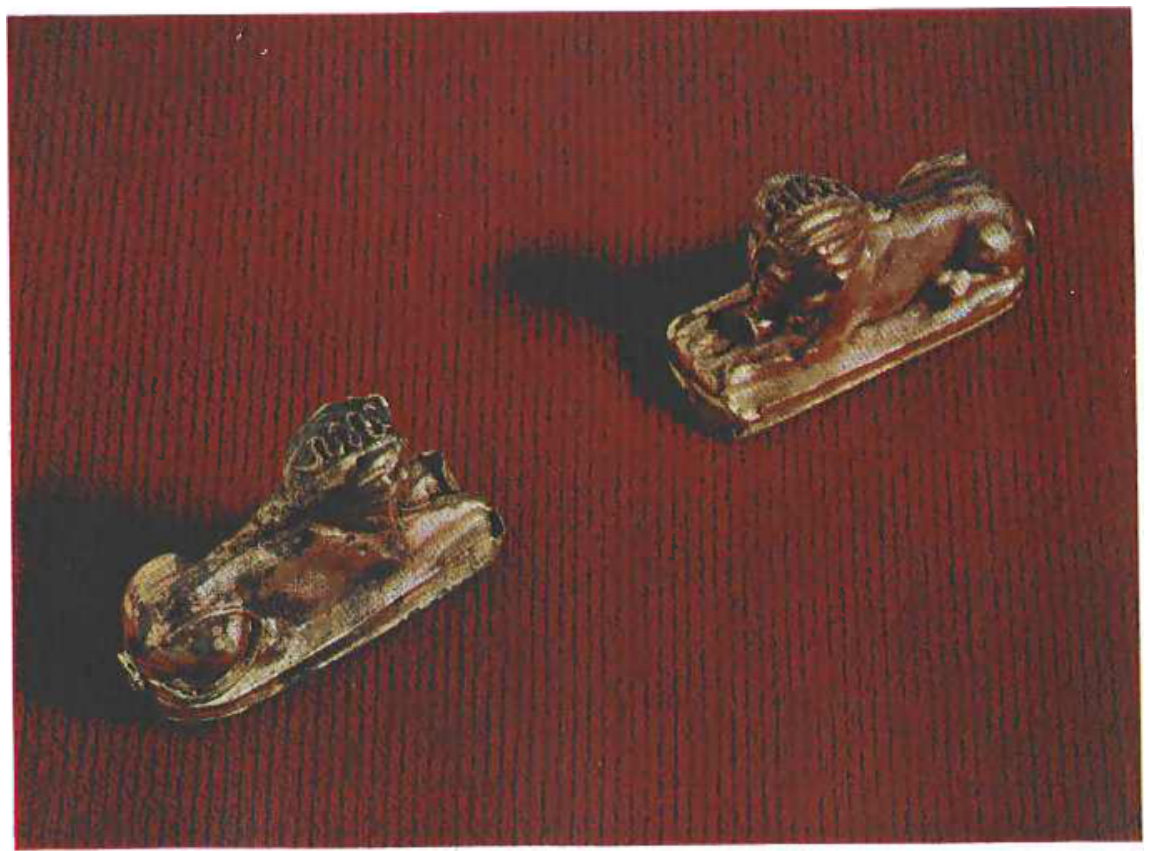


skilfully arranged in patterns and soldered or brazed into position. The resulting decoration, as may be seen from the examples shown here, gave a most artistic and pleasing effect and again the technique was adopted or followed over many centuries in the Egyptian, the Minoan, the Greek, the Etruscan and other civilisations. It became lost, however, somewhere in the time of the Roman Empire, although rather garbled descriptions are recorded by Pliny, writing in the first century A.D., and, much later, by Theophilus in his "De Diversis Artibus", written in the early part of the twelfth century.

\section{Re-discovery of the \\ Technique of Granulation}

Obviously the normal method of brazing or soldering, using a filler alloy of lower melting point, could not be used for this very fine work, with great numbers of joints to be made over a very small area and no possibility of holding a brazing alloy in position. By ingenious reasoning and research, however, the method was re-discovered some forty years ago, and almost simultaneously, by $\mathrm{Mr}$ W. T. Blackband of the Birmingham School of Arts and Crafts and by $\mathrm{Mr}$ H. A. P. Littledale, an English antiquarian and amateur goldsmith. Both lectured on their findings and demonstrated their successful attempts to reproduce Etruscan jewellery and other objects having this granulation effect, while $\mathrm{Mr}$ Littledale even obtained a British Patent (No. 415,181 of 1934) for the process!

Essentially the process employs a copper compound, preferably copper hydroxide, mixed with a proportion of glue such as Seccotine and water, this mixture being used to stick the gold wires or granules in place on the work with a fine brush. The assembly is then placed in a charcoal fire; at about $100^{\circ} \mathrm{C}$ the copper hydroxide is converted to black copper oxide, while on further heating to about $600^{\circ} \mathrm{C}$ the glue becomes carbonised. At around $850^{\circ} \mathrm{C}$ this carbon

Granulation and filigree work also developed in Egypt, beginning in about the year 2000 B.C., again probably introduced by skilled workers from Ur. By the time of Tutankhamun, around 1350 B.C., a quite exceptional degree of artistic ability and technical skill had been achieved. The hilt of the famous gold dagger of Tutankhamun is decorated with alternate bands of geometric designs in granulated gold work and of gold cloisonné with semi-precious stones. At the base of the hilt is a band of continuous spirals inside a border of rope-pattern, all applied by braxing gold wires and tiny gold spheres into position

Photograph by F. L. Kennet reduces the copper oxide to fine particles of metallic copper, evolving carbon monoxide, and when a temperature in the region of $900^{\circ} \mathrm{C}$ is reached alloying of the copper with the gold or gold alloy of the work will begin to take place. From the constitutional diagrams on page 114 it will be seen that, if the gold object is relatively pure, the alloy formed will become liquid at such a temperature, while if silver is present, as was so often the case, melting will occur at around $850^{\circ} \mathrm{C}$ or a little below.

The carbon monoxide from the charcoal fire, and also from the reduction of the copper oxide, will not only serve as a reducing agent to remove any oxide

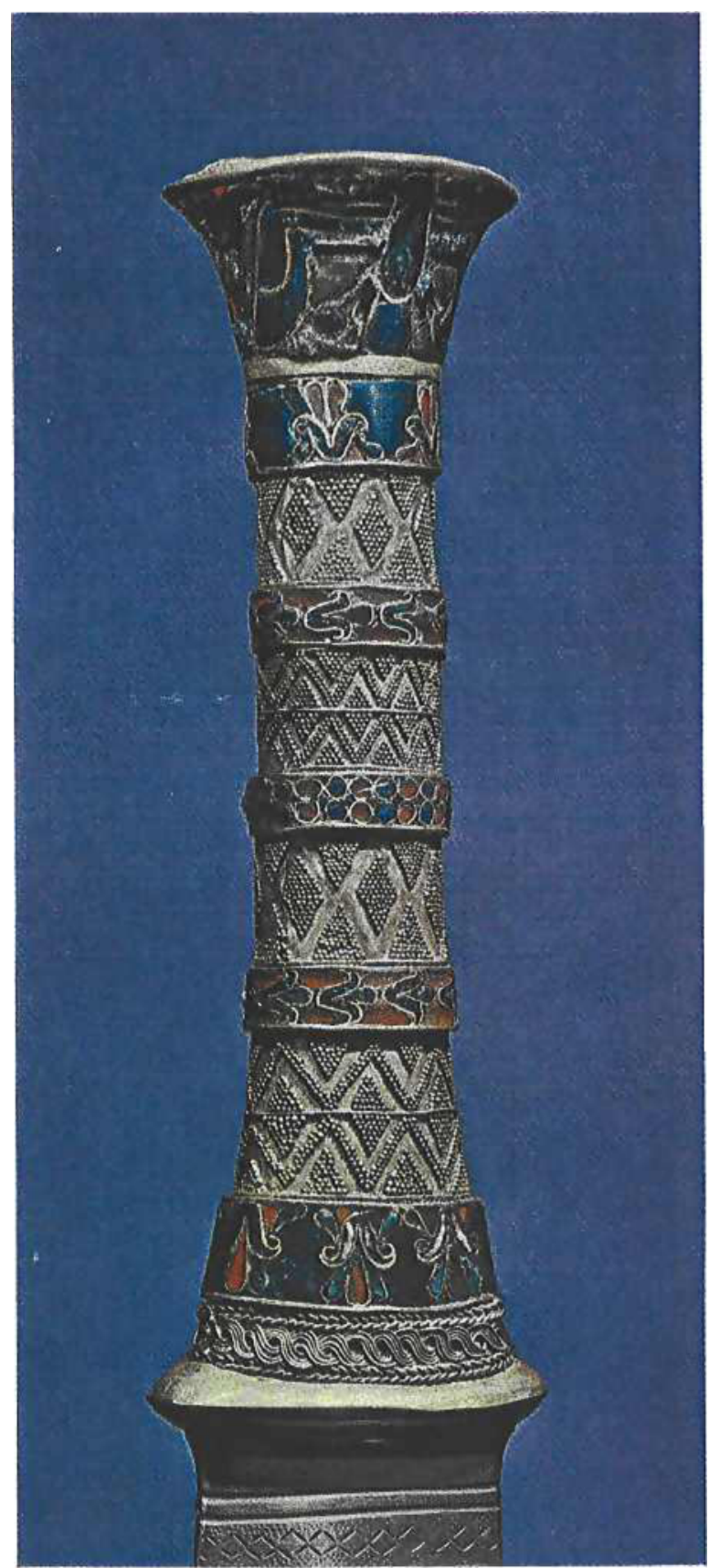


A gold alloy button or sequin, dating from ahout 1400 B.C. and found in the neighbourhood of Thebes. The shank has been gold brazed to the head, as shown in the cross-section in the centre illustration. The hottom picture is a photomicrograph of the brazed joint with a large fillet showing marked porosity. Both head and shank contained silver and copper, and were brazed together with an alloy containing more copper and slightly more silver, but the differences in melting points were so small as to call for the highest skill and craftsmanship in making the joint films on the work but also prevent the access of oxygen to the parts being heated. Thus the parent metal surface is free from oxides, and the prime requirements for the production of a brazed joint have been satisfied. The brazing alloy formed in situ will run freely, wetting the granules or wires, and the work can be removed from the fire with the brazed joints completed.

This process is known as diffusion bonding, and has also been given the name of "colloidal hard soldering" in the archaeological literature.

Pliny refers to the goldsmiths' use of copper salts -he mentions chrysocolla (a hydrated copper silicate) and verdigris (basic copper carbonate) ground up with sodium carbonate and urine in a copper mortar -and there can be little doubt that the modern re-discoverers of the process were successful in reproducing this ancient technique.

\section{Investigation of an Egyptian Brazed Joint}

Let us return now to normal or conventional brazing, using a filler alloy. Very few investigations have been made of brazed joints from the early civilisations, obviously enough as it is usually out of the question to examine valuable museum pieces by metallurgical techniques. The writer has been fortunate enough, however, through the co-operation of the British Museum, to be able to examine a small button or sequin from the area of Thebes in Egypt and dated about 1400 B.C. This was some $3.5 \mathrm{~mm}$ in diameter with a shank of $2 \mathrm{~mm}$ length, both fabricated from gold alloy sheet $0.2 \mathrm{~mm}$ in thickness. In the illustrations here the button is shown at the top, the centre picture shows its cross-section and the structure of the brazed joint, while the lower illustration is a magnified view of the joint showing a large fillet of brazing alloy having considerable porosity.
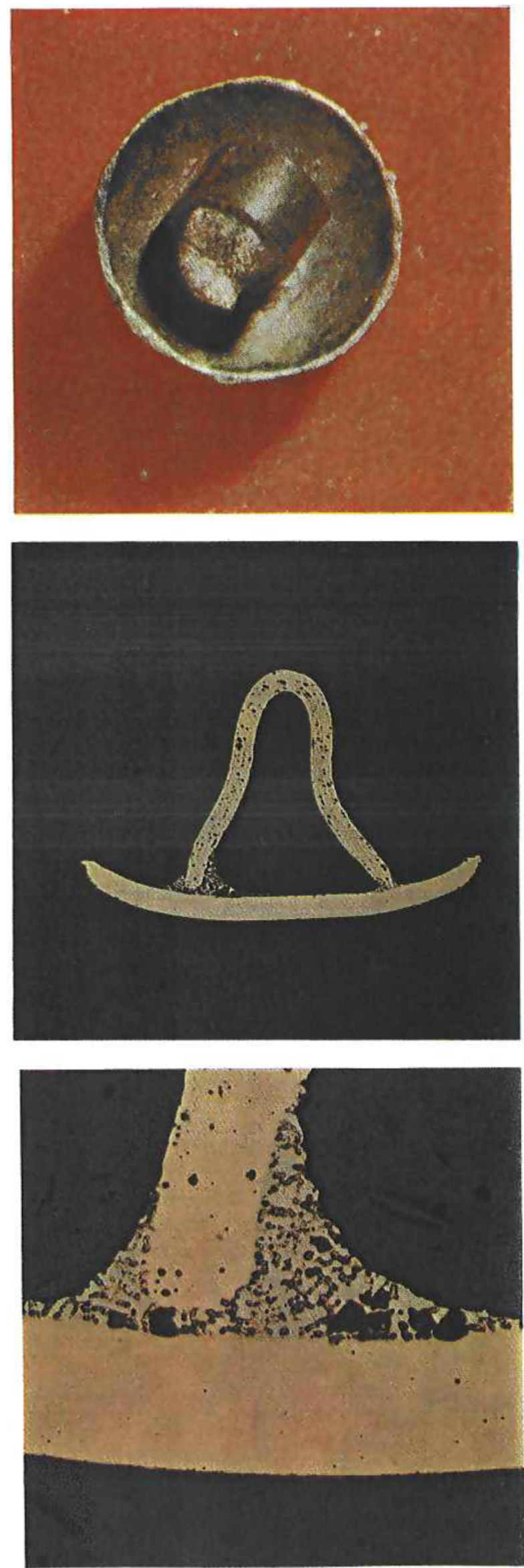


\section{Composition and Melting Points of the Alloys in the Egyptian Button}

\begin{tabular}{l|c|c|c|c|c}
\hline & $\begin{array}{c}\text { Gold } \\
\text { per cent }\end{array}$ & $\begin{array}{c}\text { Silver } \\
\text { per cent }\end{array}$ & $\begin{array}{c}\text { Copper } \\
\text { per cent }\end{array}$ & $\begin{array}{c}\text { Liquidus } \\
{ }^{\circ} \mathrm{C}\end{array}$ & $\begin{array}{c}\text { Solidus } \\
{ }^{\circ} \mathrm{C}\end{array}$ \\
\hline Head & $85.4 \pm 1.0$ & $13.4 \pm 0.9$ & $1.3 \pm 0.2$ & 1050 & 1020 \\
\hline Shank & $71.4 \pm 0.2$ & $26.1 \pm 0.2$ & $2.5 \pm 0.1$ & 1030 & 980 \\
\hline Brazed Joint & $66.7 \pm 0.6$ & $28.0 \pm 0.6$ & $5.3 \pm 0.2$ & 1010 & 920 \\
\hline
\end{tabular}

The shank of the button was a little lighter in colour than the head, and a lighter coloured layer was also visible over parts of the inner surface of the head near to the points of attachment of the loop where metal had flowed from the joints.

Electron probe micro-analysis was carried out on the head, the shank and the joint area, and the results are given in the table (with a standard deviation where multiple analyses were performed to give some idea of homogeneity) together with the liquidus and solidus temperatures of the alloys in question. The braze fillet not only contains more copper than either the head or the shank, but also slightly more silver, but it is of course likely that the joint has become enriched with gold to some extent from the parts being brazed, so that a rather lower melting range for the solder can be assumed. This would not, however, be likely to be lower than $850^{\circ} \mathrm{C}$ for the solidus and $950^{\circ} \mathrm{C}$ for the liquidus, the latter temperature being only $30^{\circ}$ below the solidus temperature of the shank!

It is clear from these results that a very high degree of temperature control will have been necessary for a brazed joint to have been made without melting the button. The modern skilled metal worker would find it extremely difficult to reproduce this small object, and yet the Egyptian craftsman who made it did so with no more equipment than a charcoal fire and a mouth blow-pipe.

\section{Acknowledgments}

The author wishes to acknowledge the valuable assistance given by the staff of the British Museum, particularly by Mr T. G. H. James and Mr S. Baker of the Department of Egyptian Antiquities and by Mr T. C. Mitchell of the Department of Western Asiatic Antiquities, and also to thank Mr J. H. F. Notton of the Johnson Matthey Research Laboratorics for carrying out the electron probe microanalyses on the Egyptian button.

B $Y$ much study and experiment the old alchemists are seeking to create not the meanest of Nature's products, but the most excellent, namely gold, which is begotten of the sun, inasmuch as it has more resemblance to it than to anything else that is and no created thing is more enduring than this gold. It is immune from destruction by fire, which has power over all the rest of created things, reducing them to ashes, glass, or smoke.

From a manuscript in the Royal Library at Windsor, translated by Edmund MacCurdy, London, 1938

\author{
LEONARDO DA VINCI \\ Dell'Anatomia \\ Milan, 1489
}

